\title{
ALPHA-2-HS-GLYCOPROTEIN (A2HS) POLYMORPHISM IN A JAPANESE POPULATION: EXISTENCE OF TWO NEW VARIANTS
}

\author{
Kazuo Umetsu, ${ }^{1}$ Isao Yuasa, ${ }^{2}$ Mitsuru Ikuta, ${ }^{3}$ \\ and Tsuneo Suzukr ${ }^{1}$ \\ ${ }^{1}$ Department of Forensic Medicine, Yamagata University School of Medicine, \\ Yamagata 990-23, Japan \\ ${ }^{2}$ Department of Legal Medicine, Tottori University of Medicine, \\ Yonago 683, Japan \\ ${ }^{3}$ Aomori Red Cross Blood Center, Aomori 030, Japan
}

\begin{abstract}
Summary The alpha-2-HS-glycoprotein (A2HS) polymorphism was studied in a Japanese population using polyacrylamide gel isoelectric focusing, followed by immunoblotting. Two new alleles, designated $A 2 H S^{*} 7$ and $A 2 H S^{*} 8$, were observed.
\end{abstract}

\section{INTRODUCTION}

Since Anderson and Anderson (1979) first described the two common alleles of alpha-2-HS-glycoprotein (A2HS), the six rare alleles have been reported: $A 2 H S^{*} 3$ (Cox and Andrews, 1983), A2HS*4 (Weidinger et al., 1984), A2HS*5 (Umetsu et al., 1984), $A 2 H S^{*} V^{\text {Gifu }}$ (Ohya et al., 1985), $A 2 H S^{*} B$ (Cox et al., 1986; Weidinger, 1986) and $A 2 H S^{*} 11$ (Westwood et al., submitted for publication). This report describes two new variants of A2HS found in Japanese.

\section{MATERIALS AND METHODS}

ACD-plasma samples were prepared from unrelated healthy individuals $(n=$ 400) living in Aomori prefecture, a northern area of Honshu island of Japan. Polyacrylamide gel $(5 \% \mathrm{~T}, 3 \% \mathrm{C}, 110 \times 120 \times 0.5 \mathrm{~mm})$ was prepared containing $0.48 \%$ $\mathrm{w} / \mathrm{v}$ Pharmalyte $\mathrm{pH} 4.2-4.9$ (Pharmacia) and $1.92 \% \mathrm{w} / \mathrm{v}$ Pharmalyte $\mathrm{pH} 4.5-5.4$. The catholyte and anolyte were $0.2 \mathrm{M} \mathrm{NaOH}$ and $0.5 \mathrm{M} \mathrm{H}_{3} \mathrm{PO}_{4}$, respectively. The gel was prerun at $10^{\circ} \mathrm{C}$ for $30 \mathrm{~min}$ at a constant power of $5 \mathrm{~W}$ and after sample (3.5 el) application, focusing was continued for $3 \mathrm{hr}$ at a constant power of $10 \mathrm{~W}$. A2HS patterns were developed by immunoblotting (Yuasa et al., 1985). The plasma 
specimens desialyzed with the method described by Umetsu et al. (1986) were also phenotyped.

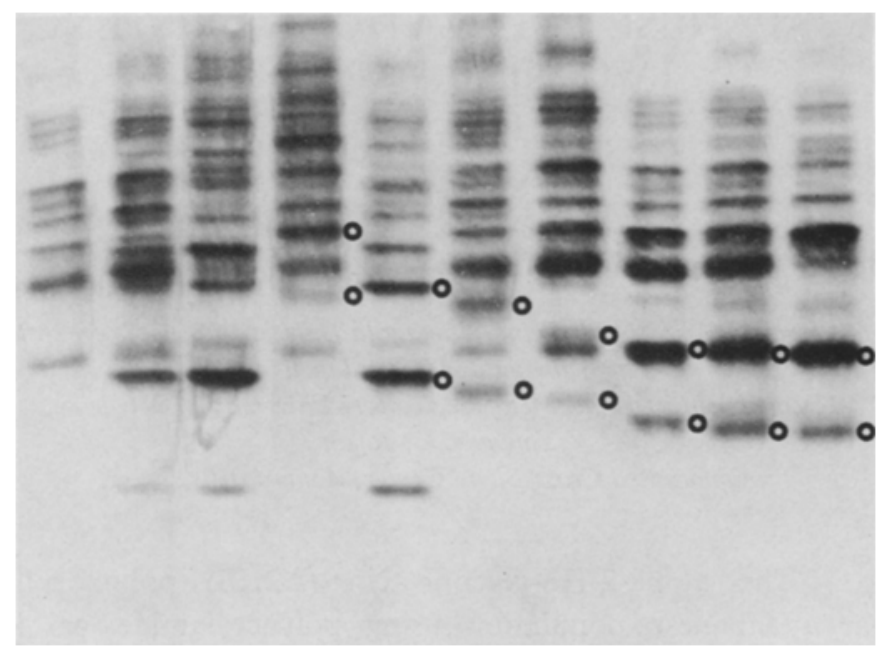

Fig. 1. Various A2HS band patterns revealed by isoelectric focusing of native plasma samples. Anode is at the top. Phenotypes from left to right: 1, 2-1, 2, 4-1, 8-2, 5-1, VGifu-1, 7-1, 11-1, and B-1. Empty circles indicate main A2HS variant bands.

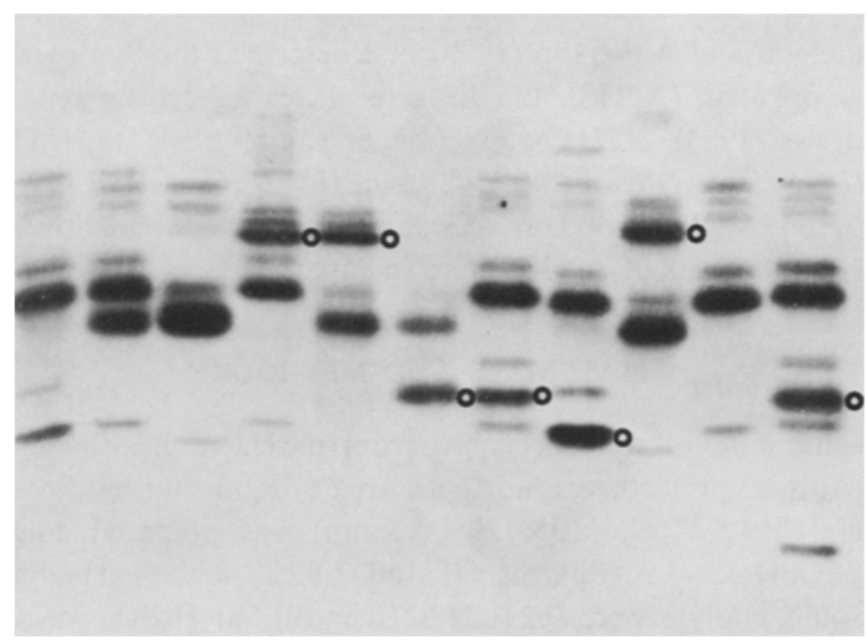

Fig. 2. Various A2HS band patterns revealed by isoelectric focusing of desialyzed plasma samples. Anode is at the top. Phenotypes from left to right: 1, 2-1, 2, 4-1, 4-2, 5-2, VGifu-1, 7-1, 8-2, B-1, and 11-1. Empty circle indicates main A2HS variant band. 
Table 1. Distribution of phenotypes and allele frequencies of A2HS types among unrelated 400 Japanese subjects.

\begin{tabular}{|c|c|c|c|c|}
\hline Phenotypes & Observed No. & $\%$ & Expected No. & $\chi^{2}$ \\
\hline 1 & 217 & 54.3 & 222.0 & 0.1126 \\
\hline $2-1$ & 158 & 39.5 & 147.5 & 0.7475 \\
\hline 2 & 19 & 4.8 & 24.5 & 1. 2347 \\
\hline $7-1$ & 4 & \multirow{4}{*}{1.5} & \multirow{4}{*}{6.0} & \multirow{4}{*}{0.0000} \\
\hline $7-2$ & 1 & & & \\
\hline $8-2$ & $1\}$ & & & \\
\hline Others & 0 & & & \\
\hline Total & 400 & 100.1 & 400.0 & 2.0948 \\
\hline
\end{tabular}

Allele frequencies: $A 2 H S^{*} I=0.74500, A 2 H S^{*} 2=0.24750, A 2 H S^{*} 7=0.00625, A 2 H S^{*} 8=0.00125$; $0.1<\mathrm{p}<0.2(\mathrm{df}=1)$.

\section{RESULTS AND DISCUSSION}

In 400 Japanese subjects A2HS patterns were classified into three common $(1,2-1,2)$ and three rare types. Three new rare types were considered to be controlled by two rare alleles and these alleles were designated $A 2 H S^{* 7}$ and $A 2 H S^{*} 8$, respectively. In the native plasma specimens, the A2HS 7 bands are located between A2HS VGifu and A2HS 11 bands, and A2HS 8 bands appear between A2HS 1 and A2HS 5 bands (Fig. 1). On the other hand, in the desialyzed plasma samples, A2HS 7 band comes out in the cathodal side of A2HS 11 band, and A2HS 8 band appears in the anodal side of A2HS 4 band (Fig. 2). In the desialyzed samples, the sequence of A2HS on the basis of their isoelectric point is as follows; in the direction of cathode, A2HS 8, A2HS 4, A2HS 1, A2HS 2, A2HS V Gifu, A2HS 5, A2HS 11, and A2HS 7. The sequence of A2HS B band was not determined because it was undetectable in the desialyzed samples.

The results of the population study for A2HS in unrelated 400 Japanese subjects are presented in Table 1. The distribution of phenotypes fitted the HardyWeinberg equilibrium.

Acknowledgments We thank Dr. Ohya (Gifu), Dr. Weidinger (München) and Dr. Westwood (Reading) for providing us with standard samples.

\section{REFERENCES}

Anderson, N.L. and Anderson, N.G. 1979. Microheterogeneity of serum transferrin, haptoglobin and $\alpha_{2}$ HS glycoprotein examined by high resolution two-dimensional electrophoresis. Biochem. Biophys. Res. Commun. 88: 256-265.

Cox, D.W. and Andrews, B.J. 1983. Silver stain immunofixation for $\alpha_{2}$ HS-glycoprotein: A new method for detection of protein heterogeneity. In Electrophoresis '82, Stathakos, D., ed., Walter de Gruyter, Berlin, pp. 243-247. 
Cox, D.W., Andrews, B.J., and Wells, D. 1986. Genetic polymorphism of $a_{2}$ HS-glycoprotein. Am. J. Hum. Genet. 38: 699-706.

Ohya, I., Iwasa, M., Komoriya, H., and Bunnai, Y. 1985. $\alpha_{2}$-HS-glycoprotein phenotypes in Gifu Prefecture. Res. Pract. Forens. Med. 28 : 5-8.

Umetsu, K., Kashimura, S., Ikeda, N., and Suzuki, T. 1984. A new $a_{2}$ HS-glycoprotein allele $\left(A H S^{*} 5\right)$ in two Japanese families. Hum. Genet. $68: 264-265$.

Umetsu, K., Yuasa, I., and Suzuki, T. 1986. The polymorphism of desialyzed $\alpha_{2}$ HS-glycoprotein (AHS): isoelectric focusing in $2.5 \mathrm{M}$ urea as a method for identification of genetic variants. Hum. Genet. 73: 372-373.

Weidinger, S., Schwarzfisher, F., Burgemeister, R., and Cleve, H. 1984. Genetic alpha-2-HS glycoprotein phenotypes demonstrated by isoelectric focusing and immunofixation, In Electrophoresis '84, Neuhoff, V., ed., Verlag Chemie, Weinheim, pp. 487-490.

Weidinger, S. 1986. Isoelektrische Fokussierung und Print Immunfixation: ein schnelles Verfahren zur Typisierung des Alpha-2-HS-glykoproteins. In Elektrophorese Forum '86, Radola, B.J., ed., Technische Universität München, Freising-Weihenstephan, pp. 156-162.

Yuasa, I., Taira, T., Suenaga, K., Ito, K., and Okada, K. 1985. Determination of $\alpha_{2} \mathrm{HS}$-glycoprotein phenotypes by isoelectric focusing and immunoblotting: polymorphic occurrence of $H S G A^{*} 5$ in Okinawa. Hum. Genet. 70: 32-34. 